\title{
Direct control of type IIA topoisomerase activity by a chromosomally encoded regulatory protein
}

\author{
Seychelle M. Vos, ${ }^{1,4}$ Artem Y. Lyubimov ${ }^{1,5}$ David M. Hershey, ${ }^{2}$ Allyn J. Schoeffler, ${ }^{1,6}$ \\ Sugopa Sengupta, ${ }^{3,7}$ Valakunja Nagaraja, ${ }^{3}$ and James $M$. Berger ${ }^{1,8,9}$ \\ ${ }^{1}$ Department of Molecular and Cell Biology, ${ }^{2}$ Deparment of Plant and Microbial Biology, University of California at Berkeley, \\ Berkeley, California 94720, USA; ${ }^{3}$ Department of Microbiology and Cell Biology, Indian Institute of Science, Bangalore 560012 , India
}

Precise control of supercoiling homeostasis is critical to DNA-dependent processes such as gene expression, replication, and damage response. Topoisomerases are central regulators of DNA supercoiling commonly thought to act independently in the recognition and modulation of chromosome superstructure; however, recent evidence has indicated that cells tightly regulate topoisomerase activity to support chromosome dynamics, transcriptional response, and replicative events. How topoisomerase control is executed and linked to the internal status of a cell is poorly understood. To investigate these connections, we determined the structure of Escherichia coli gyrase, a type IIA topoisomerase bound to YacG, a recently identified chromosomally encoded inhibitor protein. Phylogenetic analyses indicate that YacG is frequently associated with coenzyme A (CoA) production enzymes, linking the protein to metabolism and stress. The structure, along with supporting solution studies, shows that YacG represses gyrase by sterically occluding the principal DNA-binding site of the enzyme. Unexpectedly, YacG acts by both engaging two spatially segregated regions associated with small-molecule inhibitor interactions (fluoroquinolone antibiotics and the newly reported antagonist GSK299423) and remodeling the gyrase holoenzyme into an inactive, ATP-trapped configuration. This study establishes a new mechanism for the protein-based control of topoisomerases, an approach that may be used to alter supercoiling levels for responding to changes in cellular state.

[Keywords: gyrase; DNA topology; YacG; type II topoisomerase; transcription; metabolism]

Supplemental material is available for this article.

Received March 21, 2014; revised version accepted May 30, 2014.

The ability to rapidly alter the production and activity of proteins associated with housekeeping and proliferative processes is essential to allow cells to respond to environmental and developmental cues. Appropriate regulation of gene expression and cell growth can occur through a variety of mechanisms, including transcription factor activity, second messenger metabolites, and pathways such as RNAi (de Nadal et al. 2011; Castel and Martienssen 2013).

Present addresses: ${ }^{4}$ Department of Molecular Biology, Max-Planck-Institute for Biophysical Chemistry, 37077 Göttingen, Germany; ${ }^{5}$ The James H Clark Center, Stanford School of Medicine, Stanford, California 94305 USA; ${ }^{6}$ Department of Early Discovery Biochemistry, Genentech, South San Francisco, CA 94080 USA; ${ }^{7}$ Department of Molecular Biology, Presidency University, Kolkata, India; ${ }^{8}$ Department of Biophysics and Biophysical Chemistry, Johns Hopkins University School of Medicine, Baltimore, MD 21205, USA

${ }^{9}$ Corresponding author

E-mail jmberger@jhmi.edu

Article is online at http://www.genesdev.org/cgi/doi/10.1101/gad.241984. 114.
Although difficult to monitor directly, chromosome topology also serves a central part in homeotic control and response (Higgins et al. 1988; Dorman et al. 1990; Stewart et al. 1990; Merino et al. 1993; Pedersen et al. 2012; King et al. 2013). Chromosome topology is maintained by a variety of factors, including DNA-bending/ wrapping proteins and DNA supercoiling (Luijsterburg et al. 2008). Topoisomerases are a ubiquitous class of enzymes that play a key role in controlling topological status, supporting essential DNA transactions such as replication, transcription, and repair (Vos et al. 2011). Topoisomerases alter supercoiling levels and resolve chromosomal tangles by transiently breaking, moving, and rejoining different DNA segments with respect to each other (Schoeffler and Berger 2008). In turn, topoisomerase

(C) 2014 Vos et al. This article is distributed exclusively by Cold Spring Harbor Laboratory Press for the first six months after the full-issue publication date (see http://genesdev.cshlp.org/site/misc/terms.xhtml). After six months, it is available under a Creative Commons License (Attribution-NonCommercial 4.0 International), as described at http:// creativecommons.org/licenses/by-nc/4.0/. 
expression levels and activities are reciprocally influenced by DNA supercoiling and the metabolic status of the cell (Menzel and Gellert 1983; Tse-Dinh and Beran 1988; Hsieh et al. 1991; van Workum et al. 1996; Schneider et al. 1999; Champion and Higgins 2007; Rovinskiy et al. 2012). Due to their requisite action in preserving and maintaining the flow of genetic information, topoisomerases have served as the successful targets of a number of cell-killing agents, often with significant therapeutic benefit (Nitiss 2009b; Pommier et al. 2010; Collin et al. 2011).

As their nucleic acid substrates frequently bear distinctive biophysical properties and/or shapes (Schoeffler and Berger 2008), topoisomerases are frequently depicted as "stand-alone" actors that rely solely on topological features in DNA to direct their time and place of work. However, many studies have called this picture into question, revealing that in cells, topoisomerases are actually subject to multiple levels of control such as protein-protein interactions and post-translational modifications (for review, see Vos et al. 2011). At present, it has yet to be established how the vast majority of these regulatory factors and marks modulate topoisomerase activity. How topoisomerase control mechanisms are in turn integrated with feedback systems to fine-tune transcriptional output for altering metabolic state or responding to cellular environment is similarly unknown.

In bacteria, both transcription and the initiation of DNA replication are highly sensitive to the steady-state levels of DNA underwinding or overwinding (Bramhill and Kornberg 1988; Higgins et al. 1988). Supercoiling equilibrium is determined in part by RNA polymerase activity (Gamper and Hearst 1982; Rovinskiy et al. 2012) along with two topoisomerases, topo IA and gyrase (Sternglanz et al. 1981; DiNardo et al. 1982; Pruss et al. 1982; Zechiedrich et al. 2000), which counterbalance each other by adding (gyrase) or subtracting (topo IA) negative supercoils to and from DNA (Wang 1971; Gellert et al. 1976). To date, a number of distinct proteins and pharmaceutical agents have been discovered that either generally inhibit gyrase in response to specific toxins or environmental cues or trap gyrase in a covalent complex with DNA to directly induce cell death (Collin et al. 2011). While significant strides have been made in understanding how small-molecule inhibitors interfere with topoisomerase function (Pommier et al. 2010; Collin et al. 2011), how proteinaceous inhibitors of these enzymes exert specific agonistic or inhibitory effects remains a frontier question.

Here we determined how one newly discovered protein, YacG (Sengupta and Nagaraja 2008), inhibits gyrase directly. Using X-ray crystallography, we show that a zinc finger domain present in YacG prevents gyrase from binding DNA by remodeling a key loop associated with resistance to fluoroquinolone antibiotics and occluding the enzyme's principal DNA-binding site. At the same time, the extreme $\mathrm{C}$ terminus of YacG forms an extended tail that unexpectedly associates with a region of gyrase found to serve as the binding locus for a newly reported gyrase inhibitor, GSK299423 (Bax et al. 2010). Biochem- ical experiments confirm the importance of the observed interactions to YacG binding and function and show that inhibition by YacG is specific to its cognate gyrase. A C-terminal peptide encompassing both binding epitopes of YacG is sufficient to inhibit gyrase, while small-angle X-ray scattering (SAXS) experiments indicate that fulllength YacG further remodels the gyrase holoenzyme to enforce closure of its distal ATPase regions. Bioinformatic analyses of ORFs that neighbor yacG genes in different bacterial species suggest that the protein regulates gyrase in response to specific metabolic signals linked to cell growth and/or stress. Together, our study defines a novel protein-based mechanism for controlling gyrase that exploits demonstrated drug-binding loci and provides a new framework for considering how bacteria might reconfigure topoisomerase activity to suit specific cellular needs.

\section{Results}

\section{YacG preferentially binds to the $C$ terminus of $G y r B$}

Gyrase is a heterotetrameric $\left(\mathrm{GyrA}_{2} \cdot \mathrm{GyrB}_{2}\right)$ enzyme that uses three reversibly associable dimer interfaces (or "gates") to coordinate the transient, ATP-dependent breakage of one DNA duplex and the passage of a second duplex through the break. YacG is a member of the treble clef and FCS zinc finger motif families that mediate diverse functions, including protein protein and nucleic acid interactions (Grishin 2001; Krishna et al. 2003). To determine how Escherichia coli YacG and gyrase interact, we cloned, purified, and performed fluorescence anisotropy-based binding experiments with various gyrase constructs and a fluorescently labeled construct of the inhibitor. Consistent with a previous limited proteolysis study suggesting that YacG binds primarily to the C terminus of GyrB (Sengupta and Nagaraja 2008), we observed that YacG associated robustly with the fulllength gyrase tetramer, the individual GyrB subunit, and the isolated topoisomerase/primase (TOPRIM) domain of GyrB (with $\mathrm{K}_{\mathrm{d} \text {,app }}$ values ranging from 30 to $45 \mathrm{nM}$ ) (Fig. $1 \mathrm{~A}, \mathrm{~B})$. In contrast, no binding was evident when YacG was incubated with the GyrB ATPase domain. Tests using a GyrB•GyrA fusion protein (GyrBA) that lacks both an auxiliary C-terminal domain (CTD) of GyrA and the GyrB ATPase domain (Fig. 1A), but is still competent to bind and cleave DNA (Schoeffler et al. 2010), showed that YacG could bind this construct with an affinity similar to that of the full-length gyrase tetramer $\left(\mathrm{K}_{\mathrm{d}, \text { app }} 25 \mathrm{nM} \pm 6.5\right.$ $\mathrm{nM}$ ). This construct, which has been crystallized previously (Schoeffler et al. 2010), was subsequently used for follow-up structural studies.

\section{Determination of a binary YacG $\bullet$ gyrase structure}

To crystallize an E. coli YacG•GyrBA complex, the two proteins were first overexpressed and purified separately from each other (Supplemental Fig. 1) and then mixed together prior to setting up hanging drop vapor diffusion experiments. Following crystallization and the collection 


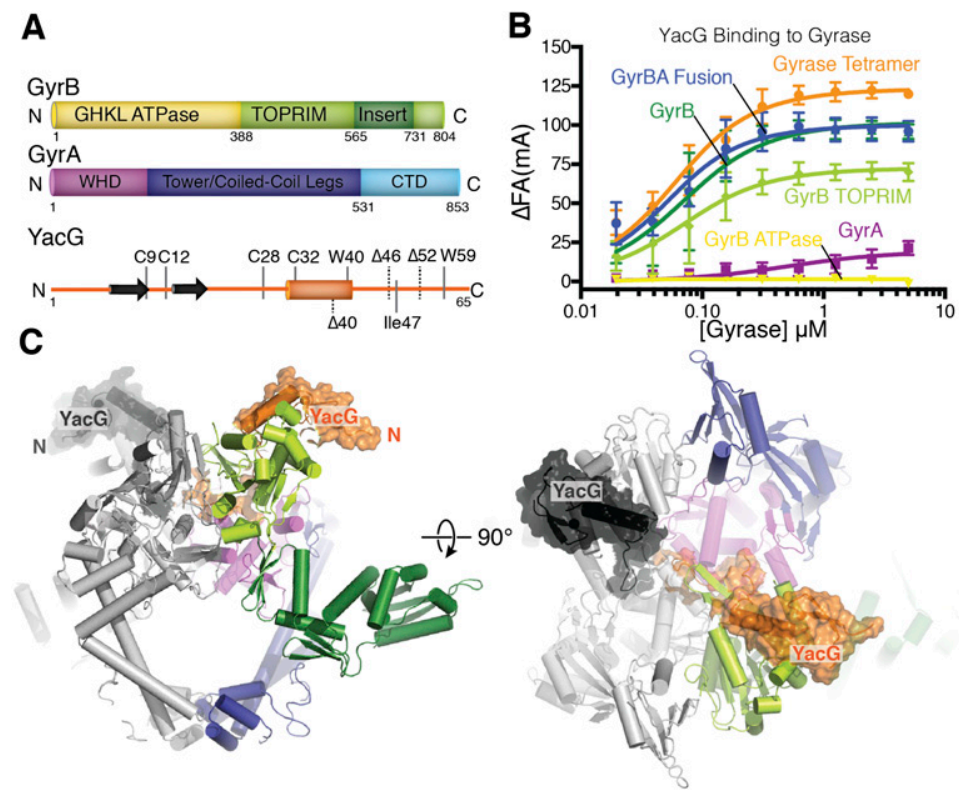

Figure 1. Structure of a YacG•Gyrase complex. $(A)$ Domain organization and primary structure of gyrase (GyrA, GyrB, and YacG abbreviations are as follows: [WHD] winged helix domain; [CTD] C-terminal domain; [GHKL] gyrase, Hsp90, DnaK, and MutL; [TOPRIM] topoisomerase/primase). Cysteines involved in zinc coordination and residues addressed in this study are marked on the primary structure of YacG. Numbers below the GyrA and GyrB sequences correspond to residues found at domain boundaries. $(B)$ Binding of YacG to $E$. coli gyrase constructs as measured by a change in fluorescence anisotropy $(\Delta \mathrm{FA}$, milli-anisotropy units). The $X$-axis relates to concentration of gyrase monomer. Data points and error bars derive from three independent experiments. $(C)$ Structure of a YacG $\bullet$ GyrBA complex. One protomer is colored gray, and the other is colored by domain as per $A$. YacG (orange/black) is shown in transparent surface. Only one GyrB insert domain (dark green) is ordered per GyrBA dimer. Except where noted, this panel and all other structural panels were rendered with PyMOL (http://www.pymol.org). of diffraction data, the structure was solved by molecular replacement (MR) using the previously reported apo structure of the E. coli GyrBA fusion as a search model (Schoeffler et al. 2010). Inspection of the resultant MR maps revealed strong difference density associated with each GyrBA dimer that could accommodate two independent copies of YacG. For the purposes of refinement, anisotropy evident in the diffraction data was accounted for by applying an ellipsoidal truncation to the structure factors (Strong et al. 2006). Following several rounds of rebuilding, refinement stabilized at an $\mathrm{R}_{\text {work }} / \mathrm{R}_{\text {free }}$ of $23.8 \% / 28.4 \%$ for the resolution range of $3.7-3.8-3.3 \AA$ (Table 1). The final model contains nearly all regions of the four copies of GyrBA and YacG present in the asymmetric unit, with the exception of a single GyrB "insert" domain (Fig. 1A) in each GyrBA homodimer that was insufficiently ordered to permit modeling (the GyrB insert is a domain found in a relatively small number of bacterial phyla that appears to stabilize gyrase during strand passage to promote rapid activity) (Schoeffler et al. 2010).

YacG remodels and occludes the DNA-binding groove of gyrase

Inspection of the GyrBA $\bullet$ YacG complex reveals that the inhibitor recognizes gyrase by a bipartite mechanism. The dominant contacts are formed by the globular zinc finger domain of YacG, which nestles against the GyrB TOPRIM fold on a portion of the domain that faces the enzyme's principal DNA-binding groove (Fig. 1C). YacG primarily associates with gyrase using its lone $\alpha$ helix and a 10-amino-acid linker that connects the helix to the two $\beta$ strands of the zinc-binding motif. Specific contacts between YacG and GyrB include residues Trp18 and Pro26 with Tyr515; residues Asp36, Lys30, and Gln33 with amino acids Arg516, Asp481, and Gln517; and residue Ile47 with His505, Leu509, Phe777, and Leu780 (Fig. 2A,B).

One particularly notable interaction between YacG and GyrB derives from the $\mathrm{C}$ terminus of the $\alpha$-helical region of the inhibitor, an element that previous nuclear magnetic resonance (NMR) studies had shown to be unstructured in the free protein (Protein Data Bank [PDB] ID 1LV3) (Fig. 2B; Ramelot et al. 2002). This segment, which is ordered in the cocrystal structure with GyrBA, places Trp40 of YacG into a hydrophobic pocket on GyrB composed of residues Met461, Leu509, Phe513, and Phe777 and the aliphatic arm of Arg516 (Fig. 2A). Trp40 is invariant in all extant YacG proteins, while the GyrB hydrophobic pocket is well conserved in all corresponding GyrB counterparts, suggesting that the interaction is important to the binding affinity of the two proteins (Supplemental Figs. 2, 3). Consistent with this idea, using phylogenetic and biochemical studies, we found that a gyrase that derives from a bacterium that lacks YacG (Mycobacterium smegmatis) and that has a slightly altered suite of amino acids in its respective TOPRIM domain is not inhibited by E. coli YacG (Supplemental Material; Supplemental Fig. 4).

The association of YacG with gyrase induces conformational changes within GyrB, particularly within a loop on the TOPRIM domain (residues 446-464) that is linked to quinolone resistance (the so-called "QRDR" motif, corresponding to residues 426-464 in E. coli GyrB) (Supplemental Fig. 2; Yoshida et al. 1991; Piton et al. 2010). The QRDR loop is unstructured in almost all type IIA topoisomerases in the absence of DNA (Fig 2C; Fu et al. 2009; Piton et al. 2010; Schoeffler et al. 2010) but becomes ordered and visible when DNA is present (Fig 2D; Dong and Berger 2007; Bax et al. 2010; Laponogov et al. 2010, 2013; Schmidt et al. 2010; Wohlkonig et al. 2010; Wendorff et al. 2012). Ordering of the QRDR loop 
Table 1. Data collection and refinement statistics

\begin{tabular}{|c|c|c|}
\hline Data collection & $\begin{array}{l}\text { Before } \\
\text { truncation }\end{array}$ & $\begin{array}{l}\text { After } \\
\text { truncation }\end{array}$ \\
\hline Resolution & $50 \AA-3.3 \AA$ & $\begin{array}{c}50 \AA \\
(3.7 \AA / 3.8 \AA / 3.3 \AA)\end{array}$ \\
\hline Wavelength & $1.1 \AA$ & $1.1 \AA$ \\
\hline Space group & $\mathrm{P} 2{ }_{1} 2_{1} 2_{1}$ & $\mathrm{P} 2{ }_{1} 2_{1} 2_{1}$ \\
\hline $\begin{array}{l}\text { Unit cell } \\
\text { dimensions }(\mathrm{a}, \mathrm{b}, \mathrm{c})\end{array}$ & $\begin{array}{c}107.2 \AA, 114.5 \AA \\
462.1 \AA\end{array}$ & $\begin{array}{c}107.2 \AA, 114.5 \AA, \\
462.1 \AA\end{array}$ \\
\hline $\begin{array}{l}\text { Unit cell } \\
\text { angles }(\alpha, \beta, \gamma)\end{array}$ & $90^{\circ}, 90^{\circ}, 90^{\circ}$ & $90^{\circ}, 90^{\circ}, 90^{\circ}$ \\
\hline $\mathrm{I} / \sigma$ & $8.1(0.3)$ & $10.4(1.4)$ \\
\hline $\mathrm{R}_{\text {merge }}{ }^{\mathrm{a}}$ & $0.083(3.41)^{\mathrm{b}}$ & $0.060(0.81)^{\mathrm{b}}$ \\
\hline $\mathrm{CC}^{1 / 2 \mathrm{c}}$ & $0.998(0.11)$ & $0.999(0.161)$ \\
\hline Completeness & $98.8 \%(99.2 \%)$ & $76.4 \%(4.6 \%)$ \\
\hline Redundancy & $2.2(2.2)$ & $1.7(0.1)$ \\
\hline Unique reflections & 86,544 & $67,314(8534)$ \\
\hline \multicolumn{3}{|l|}{ Refinement $\mathrm{d}^{\mathrm{d}}$} \\
\hline $\mathrm{R}_{\text {work }}$ (last shell) & & $23.8 \%(40.2 \%)$ \\
\hline $\mathrm{R}_{\text {free }}$ (last shell) & & $28.4 \%(41.7 \%)$ \\
\hline \multicolumn{3}{|l|}{$\begin{array}{l}\text { Structure and } \\
\text { stereochemistry }\end{array}$} \\
\hline Number of atoms & & 26792 \\
\hline Protein & & 26786 \\
\hline Ligands & & 6 \\
\hline \multicolumn{3}{|l|}{ B factor } \\
\hline Protein & & $240.3 \AA^{2}$ \\
\hline RMSD bond lengths & & $0.009 \AA$ \\
\hline RMSD bond angles & & $1.32^{\circ}$ \\
\hline \multicolumn{3}{|l|}{ Ramachandran plot ${ }^{\mathrm{e}}$} \\
\hline Favored region & & $94.0 \%$ \\
\hline Allowed region & & $5.77 \%$ \\
\hline Outliers & & $0.24 \%$ \\
\hline
\end{tabular}

${ }^{a} \mathrm{R}_{\text {merge }}=\Sigma_{\text {hkl }} \Sigma_{\mathrm{i}} \mathrm{I}_{\mathrm{i}}(\mathrm{hkl})-\mathrm{I}(\mathrm{hkl}) / \Sigma_{\mathrm{hkl}} \Sigma_{\mathrm{i}} \mathrm{I}_{\mathrm{i}}(\mathrm{hkl})$, where $\mathrm{I}_{\mathrm{i}}(\mathrm{hkl})$ is the intensity of an observation, and $\mathrm{I}(\mathrm{hkl})$ is the mean value for its unique reflection. Summations cover all reflections.

${ }^{b}$ Prior to performing ellipsoidal truncation to correct for anisotropy in the data. ${ }^{\mathrm{c}} \mathrm{CC}^{1 / 2}$ indicates correlation between intensities from random half data sets (Karplus and Diederichs 2012).

${ }^{\mathrm{d}} \mathrm{R}_{\text {work }}=\Sigma \|_{\text {hkl }}$ Fobs $|-|$ Fcalc ||$/ \Sigma_{\text {hkl }}\left|F_{\text {obs }}\right| . R_{\text {free }}$ was as per $R_{\text {work }}$ but with the reflections excluded from refinement. The $\mathrm{R}_{\text {free }}$ set was chosen using default parameters in PHENIX (Adams et al. 2010).

${ }^{\mathrm{e}}$ Ramachandran plot categories were defined by MolProbity (Chen et al. 2010).

through DNA binding masks the hydrophobic pocket occupied by Trp40 of YacG, whereas the pocket is exposed when the loop is unstructured. In the YacG・GyrBA cocrystal structure, the QRDR loop is ordered but takes on a conformation not seen previously, projecting over the gyrase active site (Fig 2E). Modeling of various DNAbound type IIA topoisomerases onto the YacG $\bullet$ GyrBA structure indicates that the rearrangement of the QRDR loop induced by the binding of YacG would sterically clash with substrate DNA (Fig 2F).

The orientation of YacG on the GyrB TOPRIM fold orients the inhibitor's $\mathrm{C}$ terminus toward the DNA cleavage center of gyrase (Fig 3). Although two copies of the YacG zinc finger domain are seen to associate with each GyrBA dimer (Fig 1C), the tip of the C-terminal tail is visible for only one of the YacG protomers in each complex (Materials and Methods). In the case of the more ordered tail, this region binds asymmetrically to GyrA, across the dyad axis that relates the winged helix domains (WHDs) of the two GyrA protomers with one another; the extended conformation and placement of the ordered tail prevents the tail of its dimer-related YacG partner from occupying the same site. Surprisingly, the position of the ordered YacG tail allows Trp59 of the protein to dock into a pocket between the GyrA WHDs that was recently shown to be a binding site for a newly discovered smallmolecule inhibitor of gyrase, GSK299423 (Fig 3; Bax et al. 2010), suggesting that the drug is exploiting a natural regulatory locus.

\section{YacG $\cdot G y r B$ interactions are required for inhibition of DNA supercoiling by gyrase}

To establish whether the specific contacts observed in the YacG•GyrBA complex are important for YacG's biochemical function, we designed, cloned, and purified several $E$. coli YacG mutants based on the structure and tested their activities against E. coli gyrase. Given its conservation and prominence in the YacG-GyrB interface, Trp40 was mutated to a smaller residue (valine). Using amino acid sequence conservation and contacts evident from the structure, we also substituted Ile47 with alanine and constructed three different truncations of the YacG C terminus (residues $\Delta 40-65, \Delta 46-65$, and $\Delta 52-65$ ) (Supplemental Figs. 1-3).

To look at the interactions between gyrase and YacG directly, we used fluorescence anisotropy to examine the ability of different YacG mutants to compete away fluorescently labeled but otherwise wild-type YacG protein from gyrase. As a positive control, unlabeled wildtype YacG proved readily able to compete for binding of the labeled inhibitor to gyrase $\left(\mathrm{K}_{\mathrm{i}, \mathrm{app}}=0.36 \mu \mathrm{M} \pm 0.12\right.$ $\mu \mathrm{M})$ (Fig 4A). Removal of the C-terminal tail of YacG (up to residue 52) only marginally reduced competition with wild-type YacG $\left(\mathrm{K}_{\mathrm{i}, \mathrm{app}}=0.96 \mu \mathrm{M} \pm 0.16 \mu \mathrm{M}\right)$, whereas more severe tail truncations greatly reduced $\left(\mathrm{YacG}^{\Delta 46-65}\right.$; $\mathrm{K}_{\mathrm{i} \text {,app }}=9.14 \mu \mathrm{M} \pm 3.8 \mu \mathrm{M}$ ) or completely abrogated $\left(Y_{a c G}{ }^{40-65}\right.$ ) competition (Fig. 4A). The YacG ${ }^{\mathrm{W} 40 \mathrm{~V}}$ mutant behaved similarly to the most extensive truncation tested, showing essentially no ability to compete wildtype YacG from gyrase (Fig. 4A). Similarly, the YacG ${ }^{\text {I47A }}$ behaved like the YacG ${ }^{\Delta 46-65}$ mutant, greatly (but not fully) reducing interference with the binding of wildtype YacG to gyrase (Supplemental Fig. 5A). Together, these data corroborate our structural observations, indicating that the C-terminal helix and extension of YacG, Trp40 in particular, are critical for robust binding to gyrase.

We next investigated the effect of our panel of wild and mutant YacG proteins on gyrase's principal activity, the ATP-dependent introduction of negative supercoils into DNA (Gellert et al. 1976). Using native agarose gel electrophoresis to monitor the topological state of a reporter plasmid, we found that wild-type YacG inhibited gyrase supercoiling activity in a dosedependent manner similar to that reported previously 
A

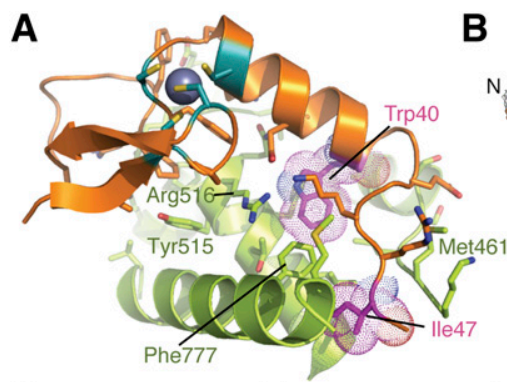

C

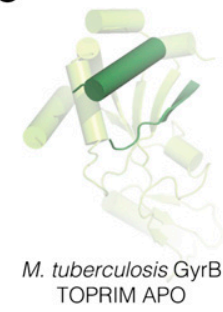

D

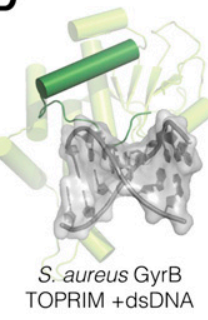

B

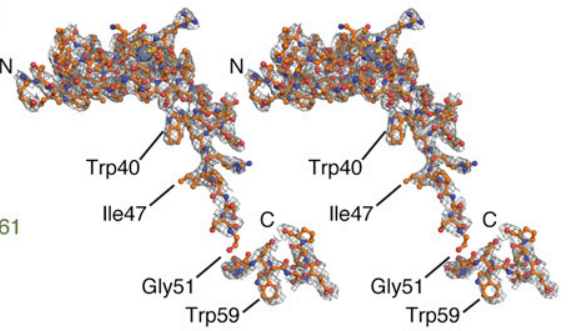

E

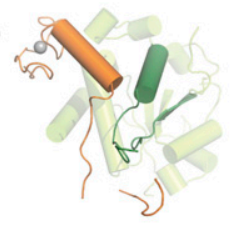

E. coli GyrB TOPRIM + YacG APO

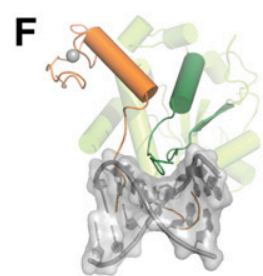

GyrB + YacG dsDNA model
Figure 2. YacG interactions with GyrBA and remodeling of the QRDR loop. (A) Close-up of the YacG zinc finger domain interaction (orange) with the GyrB TOPRIM core (green). The lone zinc ion is colored gray, and coordinating cysteines are colored marine. Interacting side chains are depicted as sticks. $(B)$ Stereo close-up of $2 \mathrm{~F}_{\mathrm{o}}-\mathrm{F}_{\mathrm{C}}$ omit map for YacG (1.3\% contour) with structural model shown as sticks. Trp 40, Ile47, and Trp59 are indicated, as is a break in the density for the YacG tail at Gly51. (C) The TOPRIM QRDR loop is disordered in the absence of a DNA substrate. The Mycobacterium tuberculosis GyrB TOPRIM domain (PDB ID 2ZJT) is shown in lime cartoon; the QRDR is dark green. $(D)$ The QRDR loop becomes ordered upon DNA binding. The Staphylococcus aureus GyrB TOPRIM domain is shown (PDB ID 2XCS) with DNA in gray. $(E)$ YacG binding remodels and orders the QRDR loop. YacG is shown in orange. $(F)$ The YacG-stabilized QRDR loop sterically overlaps with the site of DNA binding. The $S$. aureus GyrB $\cdot$ DNA model shown in $D$ is superposed on the $\mathrm{YacG} \cdot \mathrm{GyrBA}$ structure determined here.
(Fig. 4B; Sengupta and Nagaraja 2008), with gyrase supercoiling DNA $\sim 50 \%$ less effectively at a concentration of $300 \mathrm{nM}$ YacG and not all at $\sim 3 \mu \mathrm{M}$ YacG. The YacG construct bearing the least severe truncation $(\Delta 52-65)$ inhibited gyrase in a manner comparable with wild-type YacG (Fig. 4C), while the intermediate Cterminal truncation $(\Delta 46-65)$ and the Ile47Ala mutant were about threefold less effective at inhibiting supercoiling activity (Fig. 4D; Supplemental Fig. 5B). In comparison, mutation of Trp40 to valine or the removal of residues 40-65 resulted in YacG proteins that had little (if any) discernable effect on supercoiling by gyrase (Fig. 4E,F). Collectively, these data demonstrate that Trp40 and the portion of the YacG tail that binds GyrB are particularly critical determinants of YacG function.

\section{YacG blocks DNA binding to gyrase}

Based on the observed binding position of YacG on GyrB and GyrA (Figs. 1C, 2), our structure suggested that YacG inhibits gyrase by sterically preventing DNA binding. To test this model, we assessed the effects of our panel of YacG mutants on the affinity of gyrase for DNA using a fluorescence anisotropy-based binding assay. To specifically account for the effects of YacG on the binding of duplexes that associate with gyrase's DNA cleavage center, we formed gyrase tetramers from full-length GyrB and a GyrA truncation lacking an auxiliary, C-terminal DNA-binding and -wrapping domain (gyrase ${ }^{\Delta \mathrm{CTD}}$ ). Using a FITC-labeled, 37mer duplex DNA (20 nM) sufficiently long to span gyrase's central DNA-binding site, we found that our gyrase ${ }^{\Delta \mathrm{CTD}}$ construct could bind this substrate with a $\mathrm{K}_{\mathrm{d} \text {,app }}$ of $\sim 64 \mathrm{nM} \pm 9 \mathrm{nM}$ (Fig. $4 \mathrm{G}$ ), a value close

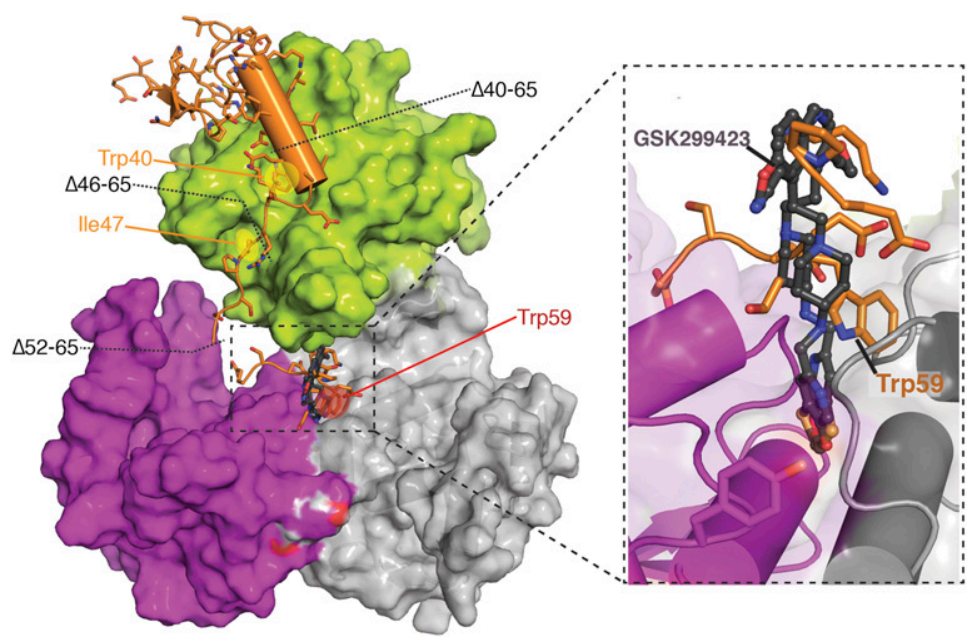

Figure 3. The $\mathrm{C}$ terminus of YacG binds to a pocket recognized by the gyrase inhibitor GSK299423. The C-terminal tail of YacG (orange) drops from the TOPRIM domain (green) into the DNA-binding floor formed by a GyrA dimer (magenta/gray). Truncation points and residues that were mutated are shown as dotted lines and colored ovals, respectively. (Inset) Close-up showing that the tail of YacG (orange sticks), Trp59 in particular, and GSK299423 (teal, modeled by superposition with PDB ID 2XCS) recognize the same GyrA locus (magenta sticks depict the active site tyrosine of GyrA for reference). 

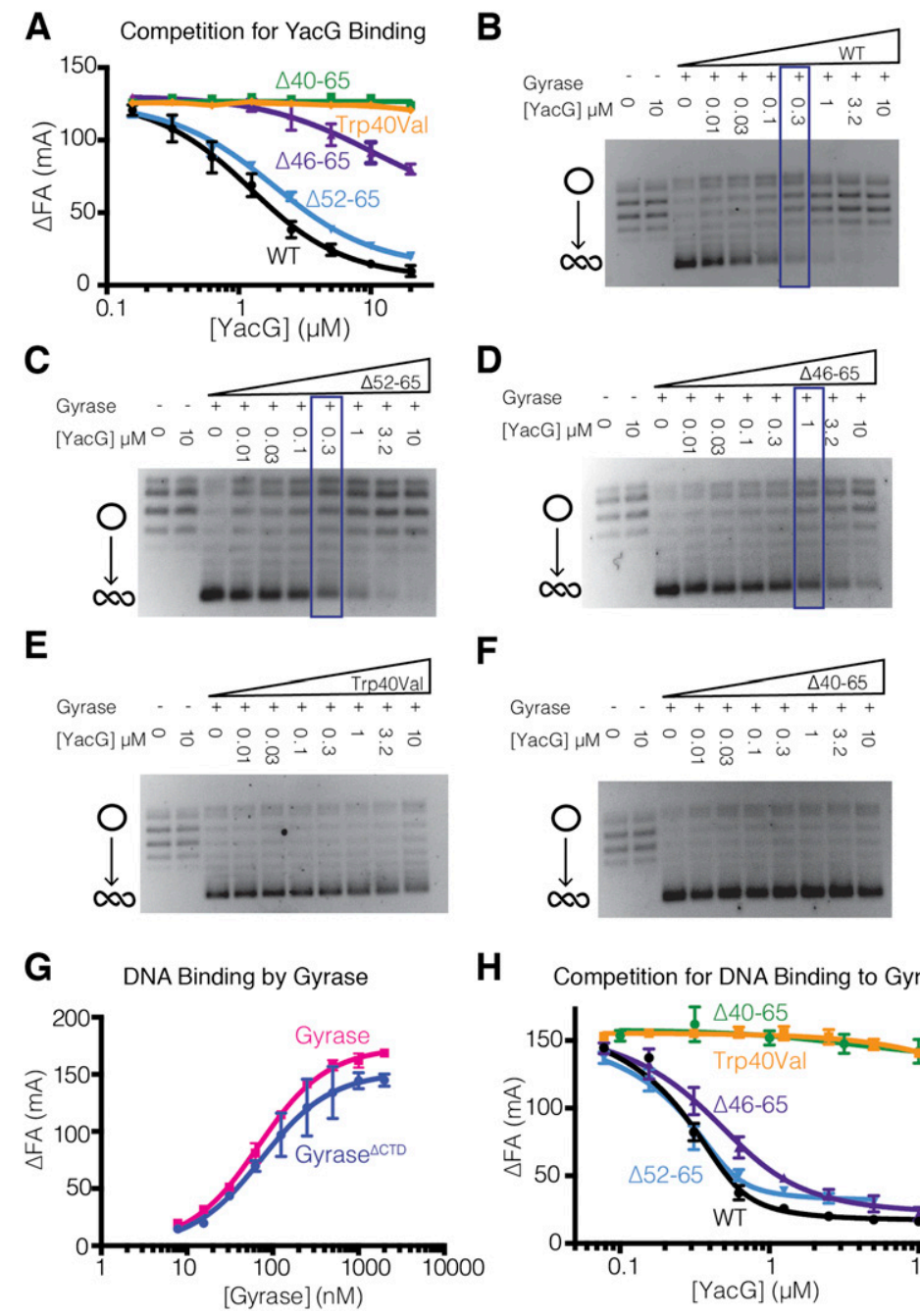

H Competition for DNA Binding to Gyrase

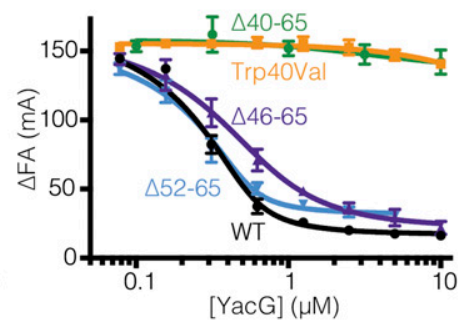

Figure 4. The YacG C-terminal region is required for gyrase inhibition. $(A)$ Binding assay showing the ability of different YacG mutants to compete away wild-type, $\mathrm{N}$-terminally labeled YacG from interacting with wildtype gyrase. Competition is evident as a decrease in fluorescence anisotropy ( $\triangle \mathrm{FA}$, milli-anisotropy units) as the labeled protein is displaced by the unlabeled competitor. $(B-E)$ DNA supercoiling assays to assess the activity of $E$. coli gyrase in the presence of various YacG mutants. Cartoons at the left of each gel represent relaxed (open circles) and negatively supercoiled (intertwined circles) topoisomers. Blue boxes correspond to the YacG concentration at which gyrase has supercoiled approximately one-half of the starting substrate. Gels are representative of at least three independent replicate experiments. (B) Wild-type (WT) YacG. $(C)$ YacG $^{\Delta 52-65 .}$ (D) $\mathrm{YacG}^{\Delta 46-65}$. (E) YacG ${ }^{\mathrm{W} 40 \mathrm{~V}}$. (F) YacG $\mathrm{Yan}^{\Delta 40}$. See also Supplemental Figures 4, E and F, and 5. $(G)$ Gyrase and gyrase $^{\Delta \mathrm{CTD}}$ bind DNA comparably. Binding by gyrase ${ }^{\Delta \mathrm{CTD}}$ (magenta) and full-length gyrase (blue) to a labeled duplex 37 mer DNA. DNA binding is evident as an increase in fluorescence anisotropy $(\Delta \mathrm{FA})$. See also Supplemental Figure 5C. $(H)$ Ability of YacG mutants to compete DNA away from binding to gyrase ${ }^{\Delta C T D}$. The same $37 \mathrm{mer}$ DNA substrate was used as per G. Competition is evident as a decrease in fluorescence anisotropy $(\Delta \mathrm{FA})$. See also Supplemental Figure 5D. to that of wild-type gyrase $\left(\mathrm{K}_{\mathrm{d}, \mathrm{app}}=58 \mathrm{nM} \pm 4 \mathrm{nM}\right)$ (Fig. 4G).

We next titrated YacG against a fixed amount of gyrase $^{\Delta C T D}$ and the FITC-labeled 37mer DNA (20 nM) using an excess of the topoisomerase compared with DNA (500 vs. $20 \mathrm{nM}$ ) to ensure that all substrate was bound in the reaction. In agreement with previous EMSA experiments (Sengupta and Nagaraja 2008), the addition of wild-type YacG resulted in a dose-dependent decrease in DNA association by gyrase $\left(\mathrm{K}_{\mathrm{i}, \mathrm{app}}=35 \mathrm{nM} \pm 11 \mathrm{nM}\right)$ (Fig. 4H). Replicates of the experiment performed in the absence of gyrase ${ }^{\Delta \mathrm{CTD}}$ resulted in no observable change in anisotropy, indicating that YacG did not associate with DNA itself (Supplemental Fig 5D). When gyrase ${ }^{\Delta C T D}$ was incubated with the least severe YacG truncation $(\Delta 52-$ $65)$, we observed an inhibition of DNA binding that was comparable with that seen for wild-type YacG $\left(\mathrm{K}_{\mathrm{i} \text {, app }}=31\right.$ $\mathrm{nM} \pm 14 \mathrm{nM})$. In contrast, the more moderate mutants $\left(\right.$ YacG $^{\Delta 46-65}$ and YacG ${ }^{\mathrm{I} 47 \mathrm{~A}}$ ) were only partially able to prevent DNA from binding to gyrase $\left(\mathrm{K}_{\mathrm{i} \text {, app }}=199 \mathrm{nM} \pm\right.$ $35 \mathrm{nM}$ ), while the most severe mutants (YacG ${ }^{\Delta 40-65}$ and $\mathrm{YacG}^{\mathrm{W} 40 \mathrm{~V}}$ ) were both unable to compete DNA off the enzyme (Fig. 4H; Supplemental Fig. 5E). Together with the placement and effect of YacG on the structure of GyrB (Figs. 1C, 2F), these data indicate that YacG operates by sterically preventing DNA from binding to gyrase and that Trp40 in particular is a so-called hot spot residue (Clackson and Wells 1995), providing key support for the YacG-gyrase interaction.

\section{The isolated $C$ terminus of YacG is sufficient for inhibiting gyrase}

Given the essential role that the C-terminal third of YacG appears to play in its inhibitory activity, we were curious whether this region alone might be sufficient to antagonize key gyrase functions. To test this idea, we first assessed whether peptides corresponding to residues 4052 and 40-65 of YacG could compete with DNA binding to the enzyme. Different concentrations of both YacG peptides were titrated against both gyrase ${ }^{\Delta C T D}(500 \mathrm{nM})$ and the labeled $37 \mathrm{mer}$ duplex used in the aforementioned DNA-binding experiments, while changes in fluorescence anisotropy were monitored at the emission maximum for the associated FITC dye. Notably, we found that whereas the shorter YacG $^{40-52}$ peptide had no effect on 
the gyrase DNA complex, the entirety of the $\mathrm{YacG}^{40-65} \mathrm{C}$ terminus was sufficient to compete gyrase off of DNA in a dose-dependent manner $\left(\mathrm{K}_{\mathrm{i} \text {, app }}=93 \mu \mathrm{M} \pm 10 \mu \mathrm{M}\right)$ (Fig. 5A). Subsequent analysis of both peptides in DNA supercoiling reactions followed a similar trend, with only the longer $\mathrm{YacG}^{40-}{ }^{65}$ peptide proving capable of blocking gyrase activity (Fig. 5B,C). Together, these data show that the isolated $C$ terminus of YacG is both necessary and sufficient to prevent gyrase from associating with and supercoiling DNA, albeit at lower efficiency compared with the full-length protein. Interestingly, although YacG inhibits gyrase with near wild-type efficacy when its $\mathrm{C}$ terminus is truncated after residue 51 (Figs. $2 \mathrm{~B}, \mathrm{~A}-\mathrm{C}, \mathrm{H}$ ), the C-terminal peptide alone required the remaining 13 amino acids (residues 53-65) to block gyrase function. This result indicates that the $\mathrm{C}$-terminal interactions formed between YacG and GyrA aid in the action of the protein against gyrase but that these contributions are largely masked by more dominant contacts between the body of YacG and GyrB, Trp40 in particular. More detailed studies will be needed to further differentiate between these relative contributions.

YacG induces ATPase domain and DNA gate closure in the gyrase holoenzyme

In addition to blocking DNA binding, E. coli YacG has been reported to diminish the basal (DNA-free) ATPase activity of gyrase (Sengupta and Nagaraja 2008). As the YacG $\bullet$ GyrBA complex imaged here lacks the ATPase domain of GyrB (Fig. 1A), an explanation for this effect was not immediately evident from the structure. To determine whether YacG might have some additional effect on the organization or architecture of the gyrase holoenzyme, we modeled our structure onto previously crystallized, near-full-length crystallographic structures of type IIA topoisomerases from Saccharomyces cerevisiae (topo II; PDB ID 4FGH) (Schmidt et al. 2012) and Streptococcus pneumoniae (topo IV; PDB ID 4I3H) (Laponogov et al. 2013), which exhibit closed and open conformations of the ATPase domains, respectively. Inspection of the resultant models suggested that YacG binding to the GyrB TOPRIM fold might allow the protein to interact with the ATPase domains when they are closed, thereby interfering with reopening to impede ATP turnover.

To test the idea that YacG might globally affect the conformation of the gyrase holoenzyme, we analyzed the solution structure of gyrase $\mathrm{SCTD}^{\Delta \mathrm{C}}$ the presence and absence of YacG by SAXS (the CTDs of GyrA were removed so as to avoid complications from their reported positional mobility) (Fig. 6A,B; Kirchhausen et al. 1985; Costenaro et al. 2005; Lanz and Klostermeier 2011). Scattering data obtained for gyrase ${ }^{\Delta \mathrm{CTD}}$ in the absence of YacG showed that the protein adopted an extended conformation with a significantly greater radius of gyration $\left(R_{g}\right)$ than that seen for samples prepared with YacG $\left(R_{g}\right.$, gyrase $=90.3 \AA \pm 1.7 \AA$ vs. $R_{g}$, gyrase $\cdot$ YacG $=62.8 \AA \pm$ $2.7 \AA$ ) (Fig. 6C). In the presence of the nonhydrolyzable ATP analog AMPPNP, gyrase ${ }^{\Delta \mathrm{CTD}}$ alone also underwent a contraction $\left(\mathrm{R}_{\mathrm{g}}=76.0 \AA \pm 0.5 \AA\right.$ ) (Fig. 6C), consistent with
A

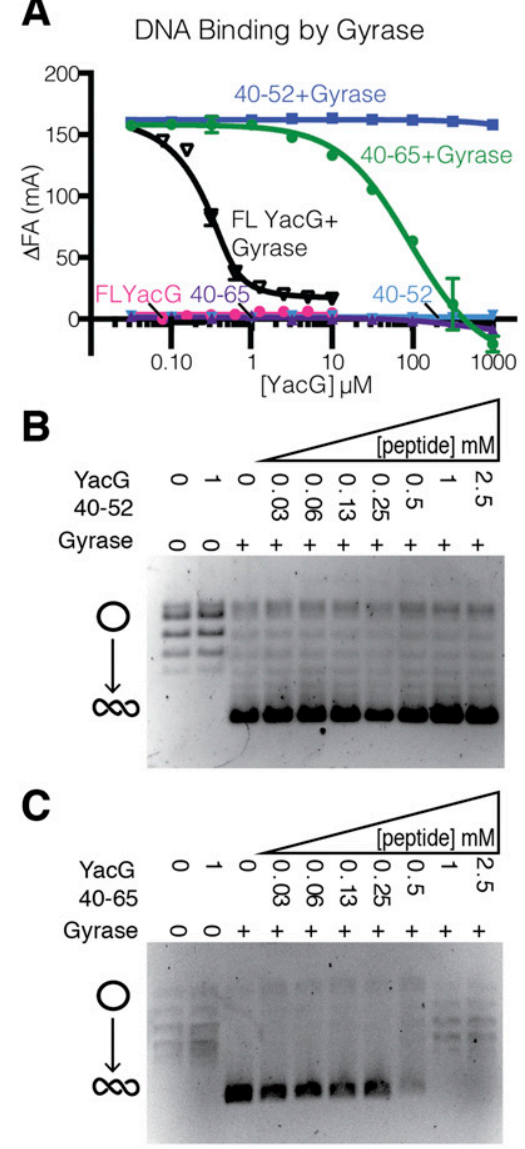

Figure 5. The $\mathrm{C}$ terminus of YacG is sufficient to inhibit gyrase. (A) Competition for DNA binding. C-terminal peptides of YacG corresponding to residues 40-52 and 40-65 were titrated against gyrase ${ }^{\Delta C T D}$ in the presence of the labeled 37 mer dsDNA substrate used in Figure 4, G and H. Competition for DNA binding is evident as a decrease in fluorescence anisotropy $(\triangle \mathrm{FA})$. Data points and error bars reflect the average and variance of three independent replicates. $(B, C)$ Effects on gyrase-mediated supercoiling. C-terminal peptides of YacG corresponding to residues 40-52 and 40-65 were titrated against E. coli gyrase in the presence of relaxed plasmid and ATP. Cartoons at the left of each gel represent relaxed (open circles) and negatively supercoiled (intertwined circles) topoisomers. (B) YacG amino acids 40-52. (C) YacG amino acids 40-65. Only the longer tail peptide containing Trp59 is able to inhibit supercoiling.

the known ability of this nucleotide to promote closure of the GyrB GHKL (gyrase, Hsp90, DnaK, and MutL) ATPase domains (Wigley et al. 1991; Ali et al. 1993; Brino et al. 2000); however, when YacG was added, the radius of gyration of the complex shrank even further $\left(\mathrm{R}_{\mathrm{g}}=59.2 \AA \pm\right.$ $2.4 \AA$ ) (Fig. 6C). This trend was recapitulated when the cross-sectional radius of gyration $(\mathrm{Rc})$, maximum interparticle distance $(\operatorname{Dmax})$, and volume of correlation $(\mathrm{Vc})$ parameters were plotted for each sample (Supplemental Fig. 6), indicating a noticeable compaction of the gyrase particle as a result of YacG binding-inspection of PorodDebye plots shows that the enzyme not only decreases in size but also has reduced flexibility (Supplemental Fig. 6; 
Rambo and Tainer 2011). Together, these data demonstrate that YacG has a stabilizing effect on gyrase, inducing global conformational changes that inhibit the relative mobility of the enzyme.

We next assessed whether specific conformations of gyrase $^{\Delta \mathrm{CTD}}$ could account for the observed scattering data. To do this, we generated a series of molecular models derived from crystal structures that represent favored conformations known or likely to be adopted by type IIA topoisomerases under different ATPase states (Supplemental Figs. 7A,B). Minimal ensemble searches (MESs) were performed with these models to identify mixtures of conformations in solution that would best fit the experimental data (Pelikan et al. 2009). Theoretical curves generated from these MESs fit poorly to the scattering data obtained from gyrase ${ }^{\triangle \mathrm{CTD}}$ in the presence and absence of nucleotide $(\chi=30.49$ in the absence of nucleotide, $x=20.30$ in the presence of AMPPNP), suggesting that gyrase ${ }^{\Delta C T D}$ molecules have significant conformational heterogeneity in solution that cannot be adequately modeled by available structures (Supplemental Fig. 7A,B). In the presence of YacG, however, MES analysis resulted in a curve that fit the gyrase ${ }^{\mathrm{CTD}}$ scattering data well $(\chi=8.10$ in the absence of nucleotide, $\chi=$ 6.14 with AMPPNP), indicating that the population primarily consists of gyrase particles in which all three dimer interfaces are self-associated (Supplemental Fig. 7A,B).

To further define the action of YacG on gyrase, we calculated three-dimensional (3D) ab initio volumes from SAXS data collected on the complex in the presence of AMPPMP (attempts to produce 3D volumes with gyrase and AMPPNP alone failed to converge on any one subset of solution volumes, again suggesting that the complex retained some conformational heterogeneity). One volume in particular that arose frequently from randomseeded calculations exhibited an elongated vase-like shape (19 of 20 runs, NSD = 0.543) (Supplemental Fig. $7 \mathrm{C})$. Docking of the YacG $\bullet$ GyrBA complex and the gyrase ATPase domains into this volume revealed that it could readily accommodate a composite model in which the ATP- and DNA-binding and cleavage regions of gyrase assume a fully dimerized conformation most similar to that seen in the AMPPNP- and DNA-bound crystal structure of yeast topo II (Fig. 6D; Schmidt et al. 2012). Together with the observed changes in $\mathrm{R}_{\mathrm{g}}$, this finding indicates that upon binding to the DNA gate of gyrase, YacG can further interact with and stabilize the association of the enzyme's ATPase domains as part of its inhibitory action.

\section{Discussion}

Although frequently considered to be relatively independent actors, multiple lines of evidence have shown that topoisomerases are actually subject to a wide number of cellular control mechanisms, ranging from protein-protein interactions to post-translational modifications (Nitiss 2009a; Vos et al. 2011). At present, how the vast majority of these regulatory systems operate at a molecular level is not understood.
A
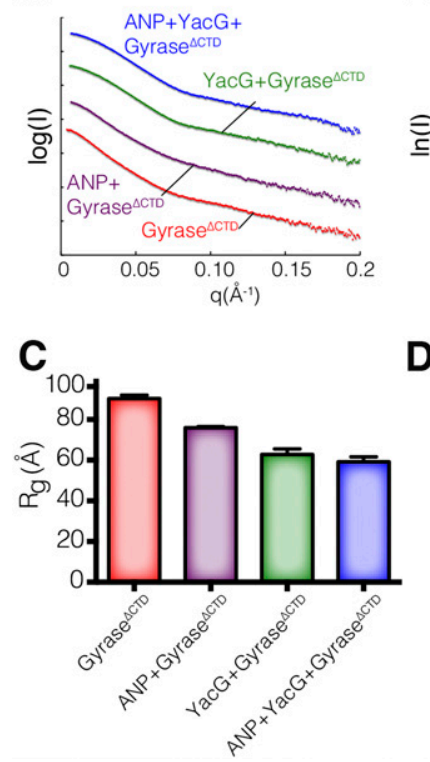

B

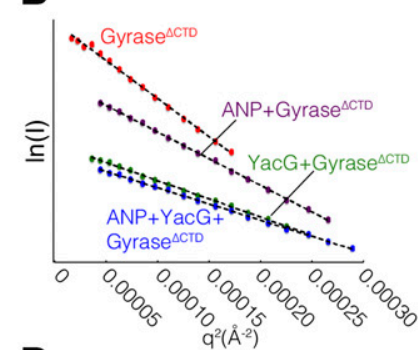

D

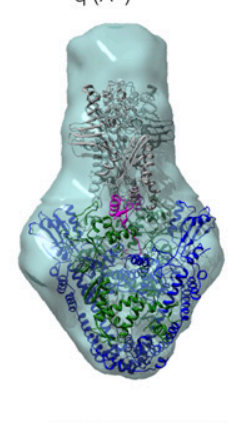

Figure 6. YacG promotes closure of gyrase dimerization interfaces. (A) Experimental SAXS curves measured with gyrase $^{\Delta C T D}$ and gyrase ${ }^{\Delta C T D} \cdot Y a c G$ in the presence and absence of $1 \mathrm{mM}$ AMPPNP (ANP). The absolute intensity of each scattering plot was adjusted by an arbitrary coefficient to facilitate side-by-side comparison. (B) Guinier plots of SAXS curves in $A$ indicate that samples are not aggregated and are homogenous. $(C)$ Radius of gyration $\left(\mathrm{R}_{\mathrm{g}}\right)$ as measured by SAXS with gyrase ${ }^{\mathrm{ACTD}}$ and gyrase ${ }^{\Delta \mathrm{CTD}} \cdot$ YacG in the presence and absence of $1 \mathrm{mM}$ AMPPNP. $(D)$ Representative ab initio model obtained from SAXS data collected from the gyrase ${ }^{\Delta \mathrm{CTD}} \cdot$ YacG complex in the presence of AMPPNP. The gyrase ${ }^{\Delta \mathrm{CTD}}$ crystal structure was modeled using the yeast holoenzyme crystal structure (PDB ID 4GFH) and colored as per Figure 1A. The figure was generated using University of California at San Francisco Chimera (Pettersen et al. 2004). See also Supplemental Figures 6 and 7.

YacG is a recently identified protein that represses the in vitro supercoiling activity of a bacterial type IIA topoisomerase, DNA gyrase (Sengupta and Nagaraja 2008). To understand how YacG interferes with gyrase function, we determined the cocrystal structure of a minimal gyrase construct comprising the central DNA-binding and cleavage region of the enzyme together with the full-length inhibitor. The structure reveals that YacG binds to both the GyrB and GyrA subunits of gyrase, remodeling a loop associated with fluoroquinolone resistance (the "QRDR") to occlude gyrase's principal DNA-binding groove. The observed restructuring of the QRDR is mediated by interactions between a C-terminal $\alpha$ helix of YacG and a hydrophobic pocket on GyrB that is surface-exposed in the absence of DNA. Biochemical experiments confirmed that contacts observed between GyrB and YacG are required for inhibitor binding to gyrase and for the YacG-dependent inhibition of both DNA binding and strand passage by the enzyme. Interestingly, we found that the $26 \mathrm{C}$-terminal amino acids of YacG are both necessary and sufficient to inhibit supercoiling and DNA binding by gyrase, provided that 
the extreme C-terminal tail, which engages a small pocket formed between the two GyrA regions, is present. Finally, using SAXS, we show that YacG compacts gyrase by stabilizing a dimerized state of the $\mathrm{N}$-terminal ATPase domains of GyrB, thereby explaining the reported ability of YacG to repress the basal ATPase rate of the enzyme (Sengupta and Nagaraja 2008).

Taken together, our data show that YacG acts by a multifaceted mechanism that targets each catalytic region of gyrase (Fig. 7A). In a cell, two copies of YacG would bind to the two GyrB TOPRIM folds present in a gyrase tetramer that is not chromosomally associated. Binding, mediated in large part by an invariant tryptophan on YacG (Trp40), would in turn remodel the QRDR loops of the two GyrB protomers and allow the extended C terminus of one YacG protomer to engage the GyrA portion of gyrase's nucleolytic center. Interestingly, the ability of a second tryptophan (Trp59) within the YacG tail to bind to the same pocket as newly identified small-molecule inhibitor of gyrase, GSK299423, suggests that the GyrAGyrA interface constitutes a natural locus for regulating enzyme function. Once stably bound, YacG would downregulate gyrase activity by preventing DNA from accessing the topoisomerase's nucleolytic center; in the presence of ATP, the zinc-binding domain of YacG would also interfere with the dissociation of gyrase's ATPase domains, further impeding both DNA binding and ATP turnover. Given that full-length gyrase binds to long DNAs much more tightly than to YacG (0.2 nM vs. $\sim 30 \mathrm{nM}$ ) (Fig. 4G; Morrison et al. 1980; Higgins and Cozzarelli 1982), the mechanism by which YacG acts would appear well suited to preventing newly synthesized gyrase from engaging DNA rather than by promoting the dissociation of gyrase molecules already bound to the chromosome.
Two key issues that remain to be addressed are when and why YacG is produced in vivo. Recent work suggests that YacG is present in cells under standard laboratory growth conditions (rich and minimal media) at levels corresponding to one YacG protein per gyrase tetramer $(\mathrm{Li}$ et al. 2014). Although the complete loss of the yacG gene appears to aid bacterial growth in response to select stress conditions (such as the cell wall-damaging agent cerulenin, the DNA-damaging agents cisplatin and nitrofurantoin, and the transcription inhibitor actinomycin D) (Nichols et al. 2011), it is presently unknown how YacG expression is regulated and what signals might increase its overall levels in the cell. Gyrase is an essential enzyme required for replication/transcription events and is targeted by both proteinaceous and pharmaceutical agents (Pommier et al. 2010; Collin et al. 2011; Vos et al. 2011). Given its ability to block access to two drug-binding loci, YacG may be up-regulated to help cells avoid accumulating DNA damage from topoisomerase poisons (such as fluoroquinolones) by decreasing the pool of active and targetable gyrase molecules through sequestration of the enzyme from DNA (S Sengupta and V Nagaraja, unpubl.). However, based on a survey of existing bacterial genomes, we propose that the principal role of YacG may be as a natural regulator of cell growth in response to metabolic status. The rationale for this idea comes from our observation that YacG is frequently found downstream from an essential metabolic protein, dephospho-coenzyme $\mathrm{A}(\mathrm{CoA})$ kinase (CoaE), and in one instance even appears to be fused to $\mathrm{CoaE}$ as part of a single polypeptide (Fig. 7B). CoaE is the last enzyme in the CoA biosynthetic pathway (Mishra et al. 2001; Leonardi et al. 2005) and acts by adding phosphate to the 3 ' ribose moiety of dephospho-CoA (Leonardi et al. 2005); the operonic
A

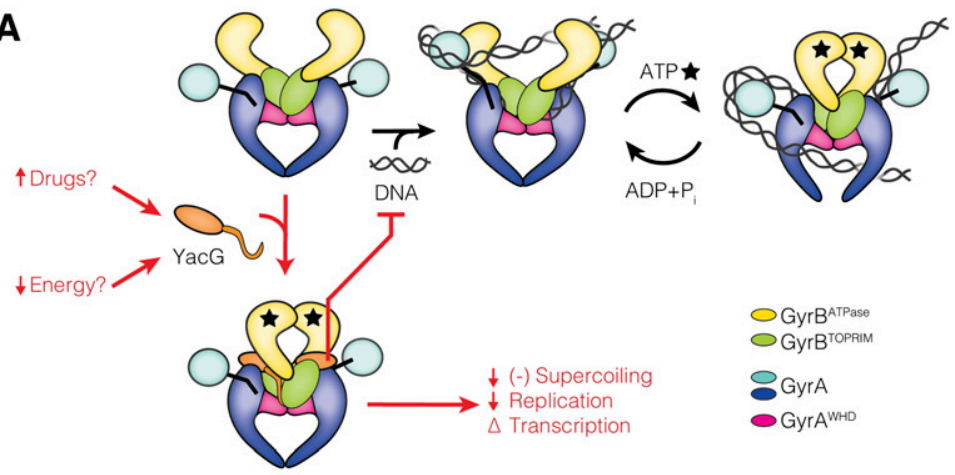

B

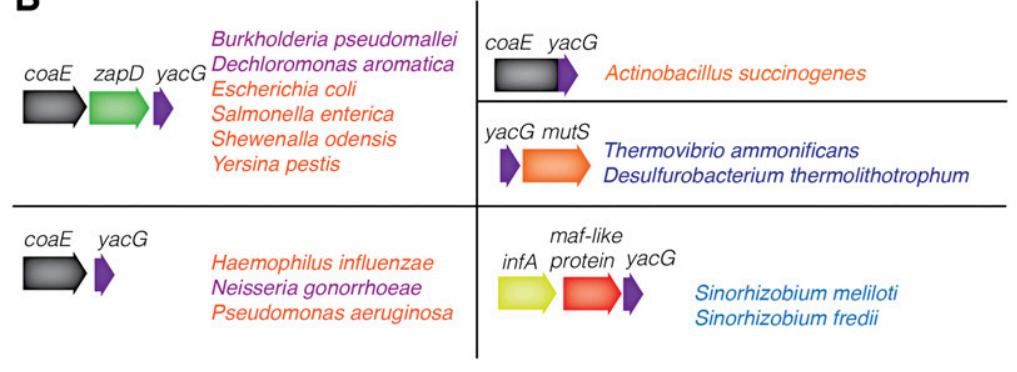

Figure 7. Impact of YacG on gyrase-dependent activities. (A) Proposed molecular mechanism of action of YacG with gyrase and YacG domains colored as per Figure 1A. Gyrase introduces negative supercoils into DNA in the presence of ATP. Production of YacG due to environmental stress would compact gyrase and prevent DNA binding, thereby inactivating the enzyme. Loss of gyrase activity would alter the net superhelical density of the bacterial chromosome, changing the cell's transcriptional profile and inhibiting DNA replication initiation. The resultant cellular quiescence may help maintain viability until the stress is removed. $(B)$ YacG operon structure from various bacterial species. Species labels are colored according to phylum/ class as in Supplemental Figure 3: $\alpha$ (cerulean), $\beta$ (purple), $\gamma$ (orange), and Proteobacteria or Aquificae (navy blue). Products from each gene correspond to dephospho-CoA kinase (coaE), FtsZ-associated protein $\mathrm{D}(z a p D)$, mismatch repair protein MutS (mutS), a maf-like protein (which inhibits septum formation), and translation initiation factor IF-1 $(\inf A)$. Some flanking genes are omitted in the displayed operons. 
linkage between CoaE and YacG suggests that conditions that result in transcription of CoaE would be likely to also produce YacG. At present, it is not known how the CoaE operon is transcriptionally regulated, although the CoA biosynthetic pathway has been shown to be subject to feedback inhibition when ATP levels are low and free CoA is available (Vallari et al. 1987; Vallari and Jackowski 1988; Song and Jackowski 1994; Yun et al. 2000).

In accord with a prospective link between YacG, gyrase, and energy status, Higgins and coworkers (Rovinskiy et al. 2012) have suggested that cell cycle-dependent changes in metabolism may be used to regulate gene expression through altered topoisomerase activity. Studies in yeast in turn have shown that cells oscillate between oxidative (ATP-producing) and reductive (glycolytic) metabolic states during a single cell cycle (Tu et al. 2005; Chen et al. 2007; Silverman et al. 2010), a switch that separates DNA-damaging reactive oxygen species from DNA replication, transcription of a majority of genes $(\sim 87 \%)$, and cell division (Tu et al. 2005; Chen et al. 2007; Silverman et al. 2010). If E. coli were to undergo similar metabolic oscillations, coexpression of $\mathrm{CoaE}$ and YacG during oxidative growth would afford cells with a means of repressing DNA replication and transcription by using gyrase as a control locus; for example, YacG could inhibit gyrase to alter the steadystate superhelical density of the chromosome, thereby blocking replication initiation and proper promoter opening, both of which are influenced by DNA supercoiling (Bramhill and Kornberg 1988; Higgins et al. 1988). In this manner, YacG would provide a complement to an orthogonal approach that cells use to couple gyrase activity to metabolic status; namely, through the relative ratio of ADP to ATP (Westerhoff et al. 1988; Hsieh et al. 1991). Future studies will be necessary to test these concepts further.

\section{Materials and methods}

Detailed experimental procedures can be found in Supplemental Material.

\section{Protein expression and purification}

All proteins were cloned into pET-based vectors and independently overexpressed in E. coli B121(DE3)RIL cells. After harvesting and lysis, proteins were purified by affinity and size exclusion chromatography, concentrated, and then either stored at $-80^{\circ} \mathrm{C}$ or used immediately.

\section{Binding assays with YacG and gyrase}

Gyrase tetramers, individual subunits, and isolated domains were mixed at different concentrations with $50 \mathrm{nM} \mathrm{N}$-terminally Alexa Fluor 488-labeled YacG in a buffer containing $120 \mathrm{mM}$ potassium glutamate, $0.12 \mathrm{mg} / \mathrm{mL}$ bovine serum albumin (BSA), $6 \mu \mathrm{M} \mathrm{ZnCl}_{2}, 12 \%$ (v/v) glycerol, and $30 \mathrm{mM}$ Tris- $\mathrm{HCl}$ (pH 7.9). Measurements were collected using a Perkin Elmer Victor 3V 1420 multilabel plate reader at $535 \mathrm{~nm}$. All points are normalized to wells that did not contain reconstituted gyrase, gyrase subunits, or gyrase domains. For competition experiments, 750
$\mathrm{nM}$ reconstituted gyrase was incubated with $50 \mathrm{nM}$ labeled wildtype YacG, and various nonlabeled YacG constructs were titrated into the solution.

\section{Crystallization}

YacG and the GyrBA fusion were dialyzed separately into a buffer containing $100 \mathrm{mM} \mathrm{KCl}, 20 \mathrm{mM}$ Tris- $\mathrm{HCl}(\mathrm{pH} 7.9)$, and $1 \mathrm{mM}$ TCEP for $16 \mathrm{~h}$ at $4^{\circ} \mathrm{C}$. The proteins were cocrystallized by vapor diffusion against a well solution of $8.3 \%(\mathrm{w} / \mathrm{v})$ PEG 3350, $30 \mathrm{mM}$ sodium cacodylate ( $\mathrm{pH} 5.0), 40 \mathrm{mM}$ potassium thiocyanate, $30 \mathrm{mM}$ spermidine, and $2.5 \mu \mathrm{M} \mathrm{ZnCl}$. For harvesting, crystals were exchanged into cryo-solution containing $25 \%(\mathrm{v} / \mathrm{v}) 1,2$ propanediol, $50 \mathrm{mM} \mathrm{KCl}, 10 \mathrm{mM}$ Tris- $\mathrm{HCl}$ (pH 7.9), $0.5 \mathrm{mM}$ TCEP, $4.7 \%$ (w/v) PEG 3350, $15 \mathrm{mM}$ sodium cacodylate ( $\mathrm{pH} 5.0), 20 \mathrm{mM}$ potassium thiocynate, $15 \mathrm{mM}$ spermidine, and $1.25 \mu \mathrm{M} \mathrm{ZnCl} 2$ and then looped and frozen in liquid nitrogen. Data were collected at the Lawrence Berkeley National Laboratory Advanced Light Source Beamline 8.3.1. Model building and refinement were carried using PHENIX, CNS, and CCP4 (Brunger et al. 1998; Brunger 2007; Adams et al. 2010; Winn et al. 2011; Afonine et al. 2012). The structure has been deposited in the PDB (ID 4TMA).

\section{Supercoiling assays}

Different amounts of purified gyrase were mixed with $5 \mathrm{nM}$ relaxed plasmid substrate in a buffer containing $0.1 \mathrm{mg} / \mathrm{mL} \mathrm{BSA}$, $10 \%$ glycerol, $0.5 \mathrm{mM}$ TCEP, $5.5 \mathrm{mM} \mathrm{MgCl} 2,5 \mu \mathrm{M} \mathrm{ZnCl}_{2}, 30$ $\mathrm{mM}$ Tris- $\mathrm{HCl}(\mathrm{pH} 7.9), 120 \mathrm{mM}$ potassium glutamate, and $2 \mathrm{mM}$ ATP (pH 7.5) (final concentrations). Reactions proceeded for 4 min at $30^{\circ} \mathrm{C}$ and were quenched by adding $2 \% \mathrm{SDS} / 20 \mathrm{mM}$ EDTA (pH 8.0) (final concentration). Samples were run on $1 \%$ $(\mathrm{w} / \mathrm{v}) \mathrm{TAE}$ agarose gels for $6-15 \mathrm{~h}$ at $2-2.5 \mathrm{~V} / \mathrm{h}$. Gels were stained with ethidium bromide and exposed to UV transillumination for visualization. For assays containing YacG, $1 \mathrm{nM}$ gyrase tetramer was incubated with a titration of YacG.

\section{DNA-binding assays}

A 37 mer FAM-labeled duplex DNA substrate (20 nM) was incubated with different concentrations of gyrase ${ }^{\Delta \mathrm{CTD}}$ in a buffer of $10 \%(\mathrm{v} / \mathrm{v})$ glycerol, $6 \mu \mathrm{M} \mathrm{ZnCl}_{2}, 0.05 \mathrm{mg} / \mathrm{mL}$ BSA, $1 \mathrm{mM}$ $\mathrm{MgCl}_{2}, 0.5 \mathrm{mM}$ TCEP, $30 \mathrm{mM}$ potassium glutamate, and $30 \mathrm{mM}$ Tris- $\mathrm{HCl}$ (pH 7.9) (final concentrations). Assays analyzing YacG were performed similarly but with $500 \mathrm{nM}$ gyrase $^{\Delta \mathrm{CTD}}$ and different concentrations of YacG protein.

\section{SAXS sample preparation and data collection}

Fresh preparations of GyrB, GyrA ${ }^{\Delta C T D}$, and YacG were used for SAXS experiments. Complexes were formed on ice in a final buffer containing $100 \mathrm{mM} \mathrm{KCl}, 20 \mathrm{mM}$ Tris- $\mathrm{HCl}(\mathrm{pH} 7.9), 5 \%(\mathrm{v} / \mathrm{v})$ glycerol, $100 \mu \mathrm{M}$ TCEP, $5 \mu \mathrm{M} \mathrm{ZnCl}_{2}$, and $6 \mathrm{mM} \mathrm{MgCl}_{2}$. Just prior to data collection at Stanford Synchrotron Radiation Lightsource (SSRL) Beamline 4-2, complexes were run over a Superose 6 column at $25^{\circ} \mathrm{C}$. Subtraction of buffer scattering (using the buffer from Superose-6 elution) was applied to yield the final scattering curves. Raw data were processed on site using SasTool (SSRL) and analyzed using ATSAS, ScÅtter, and FoxS (Petoukhov et al. 2007; Schneidman-Duhovny et al. 2010, 2013; Rambo and Tainer 2013).

\section{Acknowledgments}

We thank the Beamline 8.3.1 staff at the Advanced Light Source for advice and assistance with X-ray data collection, Darwin Li for help with reagent preparation, the staff scientists at Beamline 
4-2 of the Stanford Synchrotron Radiation Laboratory for aid in collecting SAXS data, and members of the Berger and Rine laboratories (University of California at Berkeley) for discussions and support. This work was supported by a National Science Foundation Pre-doctoral Fellowship (S.M.V.), American Cancer Society Post-doctoral Fellowship (A.Y.L.), and the National Cancer Institute (R01-CA077373; J.M.B.). S.M.V., A.J.S., A.Y.L., S.S., V.N., and J.M.B. designed the research. S.M.V. and D.M.H. purified and crystallized the proteins. S.M.V. and A.Y.L. collected X-ray and SAXS data. A.Y.L. solved, built, and refined the crystal structure and analyzed the SAXS data with input from J.M.B. S.M.V. performed all biochemical experiments and sequence analyses. S.M.V. and J.M.B. wrote the manuscript with input from the other authors.

\section{References}

Adams PD, Afonine PV, Bunkóczi G, Chen VB, Davis IW, Echols N, Headd JJ, Hung L-W, Kapral GJ, Grosse-Kunstleve RW, et al. 2010. PHENIX: a comprehensive Python-based system for macromolecular structure solution. Acta Crystallogr D Biol Crystallogr 66: 213-221.

Afonine PV, Grosse-Kunstleve RW, Echols N, Headd JJ, Moriarty NW, Mustyakimov M, Terwilliger TC, Urzhumtsev A, Zwart PH, Adams PD. 2012. Towards automated crystallographic structure refinement with phenix.refine. Acta Crystallogr D Biol Crystallogr 68: 352-367.

Ali JA, Jackson AP, Howells AJ, Maxwell A. 1993. The 43kilodalton N-terminal fragment of the DNA gyrase B protein hydrolyzes ATP and binds coumarin drugs. Biochemistry 32: 2717-2724.

Bax BD, Chan PF, Eggleston DS, Fosberry A, Gentry DR, Gorrec F, Giordano I, Hann MM, Hennessy A, Hibbs M, et al. 2010. Type IIA topoisomerase inhibition by a new class of antibacterial agents. Nature 466: 935-940.

Bramhill D, Kornberg A. 1988. Duplex opening by dnaA protein at novel sequences in initiation of replication at the origin of the E. coli chromosome. Cell 52: 743-755.

Brino L, Urzhumtsev A, Mousli M, Bronner C, Mitschler A, Oudet P, Moras D. 2000. Dimerization of Escherichia coli DNA-gyrase B provides a structural mechanism for activating the ATPase catalytic center. J Biol Chem 275: 9468-9475.

Brunger AT. 2007. Version 1.2 of the crystallography and NMR system. Nat Protoc 2: 2728-2733.

Brunger AT, Adams PD, Clore GM, DeLano WL, Gros P, GrosseKunstleve RW, Jiang J-S, Kuszewski J, Nilges M, Pannu NS. 1998. Crystallography and NMR system: a new software suite for macromolecular structure determination. Acta Crystallogr D Biol Crystallogr 54: 905-921.

Castel SE, Martienssen RA. 2013. RNA interference in the nucleus: roles for small RNAs in transcription, epigenetics and beyond. Nat Rev Genet 14: 100-112.

Champion K, Higgins NP. 2007. Growth rate toxicity phenotypes and homeostatic supercoil control differentiate Escherichia coli from Salmonella enterica serovar Typhimurium. J Bacteriol 189: 5839-5849.

Chen Z, Odstrcil EA, Tu BP, McKnight SL. 2007. Restriction of DNA replication to the reductive phase of the metabolic cycle protects genome integrity. Science 316: 1916-1919.

Chen VB, Arendall WB, Headd JI, Keedy DA, Immormino RM, Kapral GJ, Murray LW, Richardson JS, Richardson DC. 2010. MolProbity: all-atom structure validation for macromolecular crystallography. Acta Crystallogr D Biol Crystallogr 66: 12-21.

Clackson T, Wells JA. 1995. A hot spot of binding energy in a hormone-receptor interface. Science 267: 383-386.
Collin F, Karkare S, Maxwell A. 2011. Exploiting bacterial DNA gyrase as a drug target: current state and perspectives. Appl Microbiol Biotechnol 92: 479-497.

Costenaro L, Grossmann JG, Ebel C, Maxwell A. 2005. Smallangle X-ray scattering reveals the solution structure of the full-length DNA gyrase a subunit. Structure 13: 287-296.

de Nadal E, Ammerer G, Posas F. 2011. Controlling gene expression in response to stress. Nat Rev Genet 12: 833-845.

DiNardo S, Voelkel KA, Sternglanz R, Reynolds AE. 1982. Escherichia coli DNA topoisomerase I mutants have compensatory mutations in DNA gyrase genes. Cell 31: 43-51.

Dong KC, Berger JM. 2007. Structural basis for gate-DNA recognition and bending by type IIA topoisomerases. Nature 450: 1201-1205.

Dorman CJ, Ni Bhriain N, Higgins CF. 1990. DNA supercoiling and environmental regulation of virulence gene expression in Shigella flexneri. Nature 344: 789-792.

Fu G, Wu J, Liu W, Zhu D, Hu Y, Deng J, Zhang X-E, Bi L, Wang D-C. 2009. Crystal structure of DNA gyrase $B^{\prime}$ domain sheds lights on the mechanism for T-segment navigation. Nucleic Acids Res 37: 5908-5916.

Gamper HB, Hearst JE. 1982. A topological model for transcription based on unwinding angle analysis of E. coli RNA polymerase binary, initiation and ternary complexes. Cell 29: $81-90$.

Gellert M, Mizuuchi K, O'Dea M, Nash H. 1976. DNA gyrase: an enzyme that introduces superhelical turns into DNA. Proc Natl Acad Sci 73: 3872.

Grishin NV. 2001. Treble clef finger-a functionally diverse zinc-binding structural motif. Nucleic Acids Res 29: 17031714.

Higgins NP, Cozzarelli NR. 1982. The binding of gyrase to DNA: analysis by retention by nitrocellulose filters. Nucleic Acids Res 10: 6833-6847.

Higgins CF, Dorman CJ, Stirling DA, Waddell L, Booth IR, May G, Bremer E. 1988. A physiological role for DNA supercoiling in the osmotic regulation of gene expression in $S$. typhimurium and E. coli. Cell 52: 569-584.

Hsieh LS, Rouviere-Yaniv J, Drlica K. 1991. Bacterial DNA supercoiling and $[\mathrm{ATP}] /[\mathrm{ADP}]$ ratio: changes associated with salt shock. I Bacteriol 173: 3914-3917.

Karplus PA, Diederichs K. 2012. Linking crystallographic model and data quality. Science 336: 1030-1033.

King IF, Yandava CN, Mabb AM, Hsiao JS, Huang H-S, Pearson BL, Calabrese JM, Starmer J, Parker JS, Magnuson T, et al. 2013. Topoisomerases facilitate transcription of long genes linked to autism. Nature 501: 58-62.

Kirchhausen T, Wang JC, Harrison SC. 1985. DNA gyrase and its complexes with DNA: direct observation by electron microscopy. Cell 41: 933-943.

Krishna SS, Majumdar I, Grishin NV. 2003. Structural classification of zinc fingers: survey and summary. Nucleic Acids Res 31: 532-550.

Lanz MA, Klostermeier D. 2011. Guiding strand passage: DNAinduced movement of the gyrase C-terminal domains defines an early step in the supercoiling cycle. Nucleic Acids Res 39: 9681-9694.

Laponogov I, Pan X-S, Veselkov DA, McAuley KE, Fisher LM, Sanderson MR. 2010. Structural basis of gate-DNA breakage and resealing by type II topoisomerases. PLOS ONE 5: e11338.

Laponogov I, Veselkov DA, Crevel IMT, Pan X-S, Fisher LM, Sanderson MR. 2013. Structure of an 'open' clamp type II topoisomerase-DNA complex provides a mechanism for DNA capture and transport. Nucleic Acids Res 41: 99119923. 
Leonardi R, Zhang Y-M, Rock CO, Jackowski S. 2005. Coenzyme A: back in action. Prog Lipid Res 44: 125-153.

Li G-W, Burkhardt D, Gross C, Weissman JS. 2014. Quantifying absolute protein synthesis rates reveals principles underlying allocation of cellular resources. Cell 157: 624-635.

Luijsterburg MS, White MF, van Driel R, Dame RT. 2008. The major architects of chromatin: architectural proteins in bacteria, archaea and eukaryotes. Crit Rev Biochem Mol Biol 43: 393-418.

Menzel R, Gellert M. 1983. Regulation of the genes for E. coli DNA gyrase: homeostatic control of DNA supercoiling. Cell 34: 105-113.

Merino A, Madden KR, Lane WS, Champoux JJ, Reinberg D. 1993. DNA topoisomerase I is involved in both repression and activation of transcription. Nature 365: 227-232.

Mishra PK, Park PK, Drueckhammer DG. 2001. Identification of yacE (coaE) as the structural gene for dephosphocoenzyme A kinase in Escherichia coli K-12. J Bacteriol 183: 2774-2778.

Morrison A, Higgins NP, Cozzarelli NR. 1980. Interaction between DNA gyrase and its cleavage site on DNA. I Biol Chem 255: 2211-2219.

Nichols RJ, Sen S, Choo YJ, Beltrao P, Zietek M, Chaba R, Lee S, Kazmierczak KM, Lee KJ, Wong A, et al. 2011. Phenotypic landscape of a bacterial cell. Cell 144: 143-156.

Nitiss JL. 2009a. DNA topoisomerase II and its growing repertoire of biological functions. Nat Rev Cancer 9: 327-337.

Nitiss JL. 2009b. Targeting DNA topoisomerase II in cancer chemotherapy. Nat Rev Cancer 9: 338-350.

Pedersen JM, Fredsoe J, Roedgaard M, Andreasen L, Mundbjerg K, Kruhøffer M, Brinch M, Schierup MH, Bjergbaek L, Andersen AH. 2012. DNA topoisomerases maintain promoters in a state competent for transcriptional activation in Saccharomyces cerevisiae. PLoS Genet 8: e1003128.

Pelikan M, Hura GL, Hammel M. 2009. Structure and flexibility within proteins as identified through small angle X-ray scattering. Gen Physiol Biophys 28: 174-189.

Petoukhov MV, Konarev PV, Kikhney AG, Svergun DI. 2007. ATSAS 2.1-towards automated and web-supported smallangle scattering data analysis. I Appl Crystallogr 40: s223s228.

Pettersen EF, Goddard TD, Huang CC, Couch GS, Greenblatt DM, Meng EC, Ferrin TE. 2004. UCSF Chimera-a visualization system for exploratory research and analysis. J Com put Chem 25: 1605-1612.

Piton J, Petrella S, Delarue M, André-Leroux G, Jarlier V, Aubry A, Mayer C. 2010. Structural insights into the quinolone resistance mechanism of Mycobacterium tuberculosis DNA gyrase. PLOS ONE 5: e12245.

Pommier Y, Leo E, Zhang H, Marchand C. 2010. DNA topoisomerases and their poisoning by anticancer and antibacterial drugs. Chem Biol 17: 421-433.

Pruss GJ, Manes SH, Drlica K. 1982. Escherichia coli DNA topoisomerase I mutants: increased supercoiling is corrected by mutations near gyrase genes. Cell 31: 35-42.

Rambo RP, Tainer JA. 2011. Characterizing flexible and intrinsically unstructured biological macromolecules by SAS using the Porod-Debye law. Biopolymers 95: 559-571.

Rambo RP, Tainer JA. 2013. Accurate assessment of mass, models and resolution by small-angle scattering. Nature 496: $477-481$.

Ramelot TA, Cort JR, Yee AA, Semesi A, Edwards AM, Arrowsmith CH, Kennedy MA. 2002. NMR structure of the Escherichia coli protein YacG: a novel sequence motif in the zinc-finger family of proteins. Proteins 49: 289-293.

Rovinskiy N, Agbleke AA, Chesnokova O, Pang Z, Higgins NP. 2012. Rates of gyrase supercoiling and transcription elonga- tion control supercoil density in a bacterial chromosome. PLoS Genet 8: e1002845.

Schmidt BH, Burgin AB, Deweese JE, Osheroff N, Berger JM. 2010. A novel and unified two-metal mechanism for DNA cleavage by type II and IA topoisomerases. Nature 465: 641-644.

Schmidt BH, Osheroff N, Berger JM. 2012. Structure of a topoisomerase II-DNA-nucleotide complex reveals a new control mechanism for ATPase activity. Nat Struct Mol Biol 19: 1147-1154.

Schneider R, Travers A, Kutateladze T, Muskhelishvili G. 1999. A DNA architectural protein couples cellular physiology and DNA topology in Escherichia coli. Mol Microbiol 34: 953964.

Schneidman-Duhovny D, Hammel M, Sali A. 2010. FoXS: a Web server for rapid computation and fitting of SAXS profiles. Nucleic Acids Res 38: W540-W544.

Schneidman-Duhovny D, Hammel M, Tainer JA, Sali A. 2013. Accurate SAXS profile computation and its assessment by contrast variation experiments. Biophys J 105: 962-974.

Schoeffler AJ, Berger JM. 2008. DNA topoisomerases: harnessing and constraining energy to govern chromosome topology. Q Rev Biophys 41: 41-101.

Schoeffler AJ, May AP, Berger JM. 2010. A domain insertion in Escherichia coli GyrB adopts a novel fold that plays a critical role in gyrase function. Nucleic Acids Res 38: 7830-7844.

Sengupta S, Nagaraja V. 2008. YacG from Escherichia coli is a specific endogenous inhibitor of DNA gyrase. Nucleic Acids Res 36: 4310.

Silverman SJ, Petti AA, Slavov N, Parsons L, Briehof R, Thiberge SY, Zenklusen D, Gandhi SJ, Larson DR, Singer RH, et al. 2010. Metabolic cycling in single yeast cells from unsynchronized steady-state populations limited on glucose or phosphate. Proc Natl Acad Sci 107: 6946-6951.

Song WJ, Jackowski S. 1994. Kinetics and regulation of pantothenate kinase from Escherichia coli. I Biol Chem 269: 27051-27058.

Sternglanz R, DiNardo S, Voelkel K, Nishimura Y, Hirota Y, Becherer K, Zumstein L, Wang J. 1981. Mutations in the gene coding for Escherichia coli DNA topoisomerase I affect transcription and transposition. Proc Natl Acad Sci 78: 2747.

Stewart AF, Herrera RE, Nordheim A. 1990. Rapid induction of c-fos transcription reveals quantitative linkage of RNA polymerase II and DNA topoisomerase I enzyme activities. Cell 60: 141-149.

Strong M, Sawaya MR, Wang S, Phillips M, Cascio D, Eisenberg D. 2006. Toward the structural genomics of complexes: crystal structure of a PE/PPE protein complex from Mycobacterium tuberculosis. Proc Natl Acad Sci 103: 8060-8065.

Tse-Dinh Y-C, Beran RK. 1988. Multiple promoters for transcription of the Escherichia coli DNA topoisomerase I gene and their regulation by DNA supercoiling. $J$ Mol Biol 202: 735-742.

Tu BP, Kudlicki A, Rowicka M, McKnight SL. 2005. Logic of the yeast metabolic cycle: temporal compartmentalization of cellular processes. Science 310: 1152-1158.

Vallari DS, Jackowski S. 1988. Biosynthesis and degradation both contribute to the regulation of coenzyme A content in Escherichia coli. J Bacteriol 170: 3961-3966.

Vallari DS, Jackowski S, Rock CO. 1987. Regulation of pantothenate kinase by coenzyme A and its thioesters. I Biol Chem 262: 2468-2471.

van Workum M, van Dooren SJ, Oldenburg N, Molenaar D, Jensen PR, Snoep JL, Westerhoff HV. 1996. DNA supercoiling depends on the phosphorylation potential in Escherichia coli. Mol Microbiol 20: 351-360. 
Vos SM, Tretter EM, Schmidt BH, Berger JM. 2011. All tangled up: how cells direct, manage and exploit topoisomerase function. Nat Rev Mol Cell Biol 12: 827-841.

Wang J. 1971. Interaction between DNA and an Escherichia coli protein $\omega$. J Mol Biol 55: 523-533, IN16.

Wendorff TJ, Schmidt BH, Heslop P, Austin CA, Berger JM. 2012. The structure of DNA-bound human topoisomerase II $\alpha$ : conformational mechanisms for coordinating inter-subunit interactions with DNA cleavage. J Mol Biol 424: 109124.

Westerhoff HV, O'Dea MH, Maxwell A, Gellert M. 1988. DNA supercoiling by DNA gyrase: a static head analysis. Cell Biophys 12: 157-181.

Wigley DB, Davies GJ, Dodson EJ, Maxwell A, Dodson G. 1991. Crystal structure of an N-terminal fragment of the DNA gyrase B protein. Nature 351: 624-629.

Winn MD, Ballard CC, Cowtan KD, Dodson EJ, Emsley P, Evans PR, Keegan RM, Krissinel EB, Leslie AGW, McCoy A, et al. 2011. Overview of the CCP4 suite and current developments. Acta Crystallogr D Biol Crystallogr 67: 235-242.

Wohlkonig A, Chan PF, Fosberry AP, Homes P, Huang J, Kranz M, Leydon VR, Miles TJ, Pearson ND, Perera RL, et al. 2010. Structural basis of quinolone inhibition of type IIA topoisomerases and target-mediated resistance. Nat Struct Mol Biol 17: 1152-1153.

Yoshida H, Bogaki M, Nakamura M, Yamanaka LM, Nakamura S. 1991. Quinolone resistance-determining region in the DNA gyrase gyrB gene of Escherichia coli. Antimicrob Agents Chemother 35: 1647-1650.

Yun M, Park CG, Kim JY, Rock CO, Jackowski S, Park HW. 2000. Structural basis for the feedback regulation of Escherichia coli pantothenate kinase by coenzyme A. I Biol Chem 275: 28093-28099.

Zechiedrich EL, Khodursky AB, Bachellier S, Schneider R, Chen D, Lilley DM, Cozzarelli NR. 2000. Roles of topoisomerases in maintaining steady-state DNA supercoiling in Escherichia coli. J Biol Chem 275: 8103-8113. 


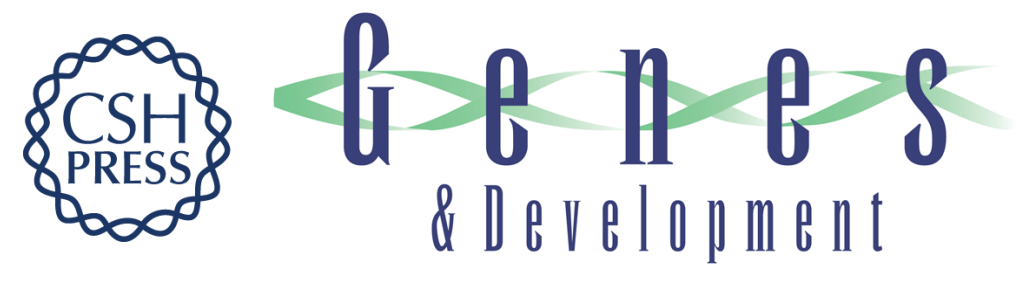

\section{Direct control of type IIA topoisomerase activity by a chromosomally encoded regulatory protein}

Seychelle M. Vos, Artem Y. Lyubimov, David M. Hershey, et al.

Genes Dev. 2014, 28:

Access the most recent version at doi:10.1101/gad.241984.114

\section{Supplemental Material \\ http://genesdev.cshlp.org/content/suppl/2014/07/02/28.13.1485.DC1}

References

This article cites 82 articles, 19 of which can be accessed free at: http://genesdev.cshlp.org/content/28/13/1485.full.html\#ref-list-1

Creative This article is distributed exclusively by Cold Spring Harbor Laboratory Press for the first Commons License

Email Alerting Service six months after the full-issue publication date (see http://genesdev.cshlp.org/site/misc/terms.xhtml). After six months, it is available under a Creative Commons License (Attribution-NonCommercial 4.0 International), as described at http://creativecommons.org/licenses/by-nc/4.0/.

Receive free email alerts when new articles cite this article - sign up in the box at the top right corner of the article or click here.

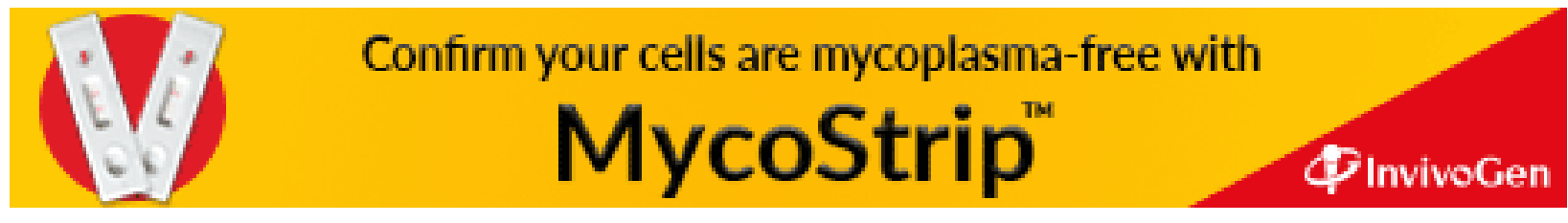

